\title{
Experience of Managing Snake Bite Cases in a Medicine Unit of Tertiary Care Hospital in Bangladesh - A Case Series
}

\author{
Md. Abu Bakar Siddique ${ }^{1}$, Md. Mujibur Rahman ${ }^{1}$, A. K. M Humayon Kabir ${ }^{1}$, Md. Uzzwal Mallik${ }^{1}$, Md. \\ Habibullah' ${ }^{1}$, Md. Mehedi Hassan ${ }^{1}$, Mostofa Kamal Chowdhury ${ }^{1}$
}

\begin{abstract}
Background: Snakebite is a neglected public health problem in many countries of the world. Being a tropical country Bangladesh is also facing this problem. In this case series we have tried to focus the illiteracy, prejudice and mismanagement happen in snake bite cases from primary to tertiary level and how effective management can save life of snake bite victim.
\end{abstract}

Case presentation: Among the 29 snake bite cases admitted in a medicine ward of tertiary care hospital four were venomous bites- two male and two female. Our patients came from around Dhaka city. Though victim failed to bring the snake, by studying clinical features and syndromic approaches we suspected Kraits as the culprit in three cases and Cobra in one case. Time period between bite and attend to hospital ranged from $4 \mathrm{hr}$ to 16.30 hours. All victims had inappropriate application of tourniquet to their limbs as a first aid management. Most of them first visit OZHA (traditional healer). Two of them developed respiratory failure. All cases were managed in ICU with polyvalent ASV. One developed anaphylaxis which was managed with adrenaline. All patients recovered completely.

Conclusion: Arrival to hospital without delay, facilities for management with trained physicians and proper supply of ASV may reduce death from snake bite and reduce financial burden to the patient. Developing public awareness to remove prejudice about snakes and identifying venomous snake bite is also necessary.

Keywords: Snake bite, Anti Snake Venom (ASV), Bangladesh

(c) (i) (2) (2)

Copyright: (C) 2021 NonCommercial-NoDerivatives 4.0 International License, which permits use, distribution and reproduction in any medium, provided the original work is properly cited, is not changed in any way and it is not used for commercial purposes.

Received: 26 November, 2020;

DOI: https://doi.org//0.3329/jom.v22il.5/397 . This is an open access article published under the Creative Commons Attribution-

Accepted: 10 December, 2020

\section{Background}

Snake bite is a neglected public health problem globally. ${ }^{1}$ It has been estimated that around 4,210000(?) envenoming occur worldwide every year with 22,000 deaths. ${ }^{2}$ In Bangladesh, an epidemiological study in 2016 showed envenomation rate was $10.98 / 100,000$ with fatality rate of 1.22/100,000 each year. ${ }^{3}$ A previous study in 2009 showed annual incidence $623.4 / 100000$ persons-year. ${ }^{4}$ There are 82 species of snakes in Bangladesh amongst which 28 species are venomous. ${ }^{5}$ Common species are Cobra, Krait, Russel's viper and Saw scaled viper. High population density, widespread agricultural activities, presence of various venomous snake species and lack of effective snake bite control programs favor the high

1. Department of Medicine, Dhaka Medical college Hospital Corresponding author: Md. Abu Bakar Siddique, Dhaka Medical college Hospital. E-mail: drzaber.mmc@gmail.com burden of snake bites. Most victims at first visit go to 'OZHA' or 'Kaviraj' for conventional and spiritual treatment, causing undue delay in reaching hospital. The interval between the bite and death is less than 6 hours in most cases. ${ }^{6}$ In Bangladesh, the only available anti-snake venom is polyvalent, which is although effective, but expensive and not available everywhere. Health care personnel, in most of the cases often lack of knowledge about proper management. Lack of awareness and knowledge about snake bite among the population make it more difficult to manage. In this report we have tried to find out the burden of snake bite in a single medical unit of a tertiary care hospital during a single snake bite season and to see how effectively snake bite patients can be managed and to observe the clinical outcome with appropriate treatment. 


\section{Case Presentation:}

During the period of July to October 2016, a total of 1551 patients were admitted in a single medical unit with $29(1.9 \%)$ snake bite cases. The age of the victims ranging from 13 to 65 years. Among 29 cases 14 (48.27\%) were male and 15 $(51.73 \%)$ were female. There were $04(13.8 \%)$ venomous snake bite cases of which 2 were male and 2 were female, age between 21 to 29 years. The bites were suspected to be by cobra in 1 and Krait in 3 cases. Time period between bite and attend to hospital ranged from $4 \mathrm{hr}$ to $16.30 \mathrm{hr}$ (average mean $10.37 \pm 5.25 \mathrm{hr}$ ). Seventy five percent of venomous bite cases at first went to OZHAS for treatment. All venomous cases were managed in the intensive care unit (ICU). The details of the cases are given in the table.

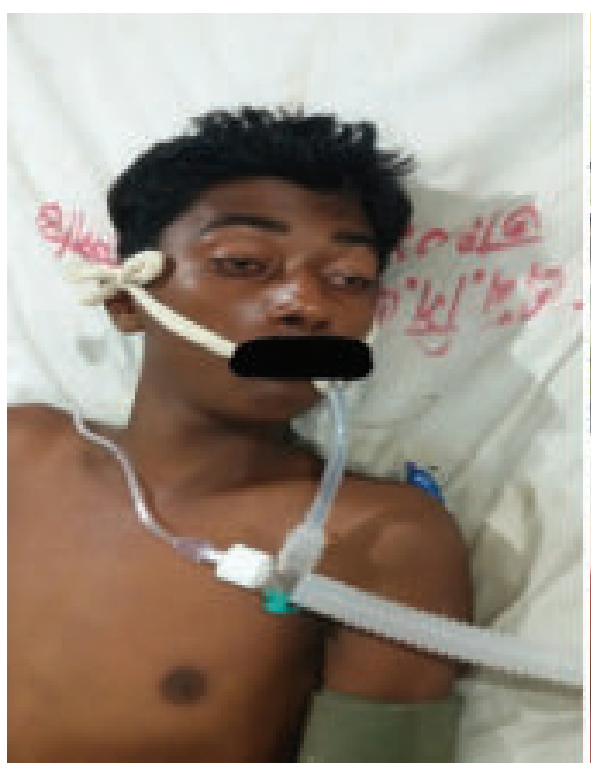

Case 1(a) before treatment

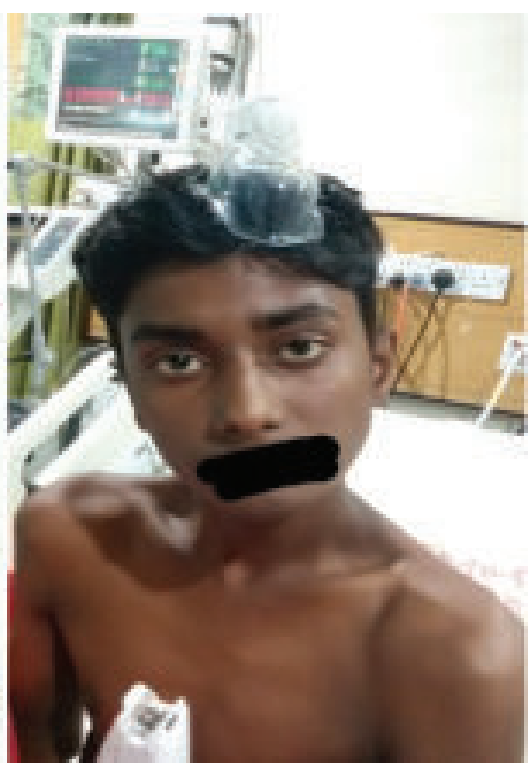

Case 1 (b) after treatment

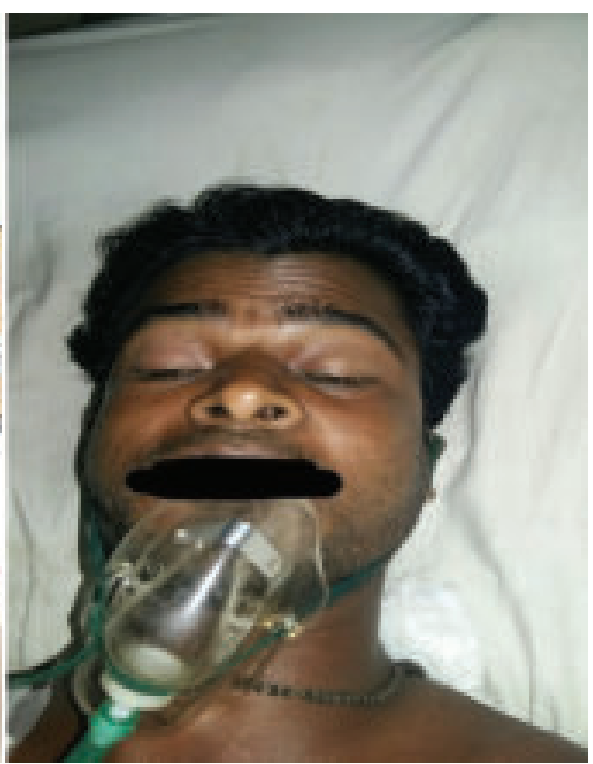

Case 2 (a) before treatment

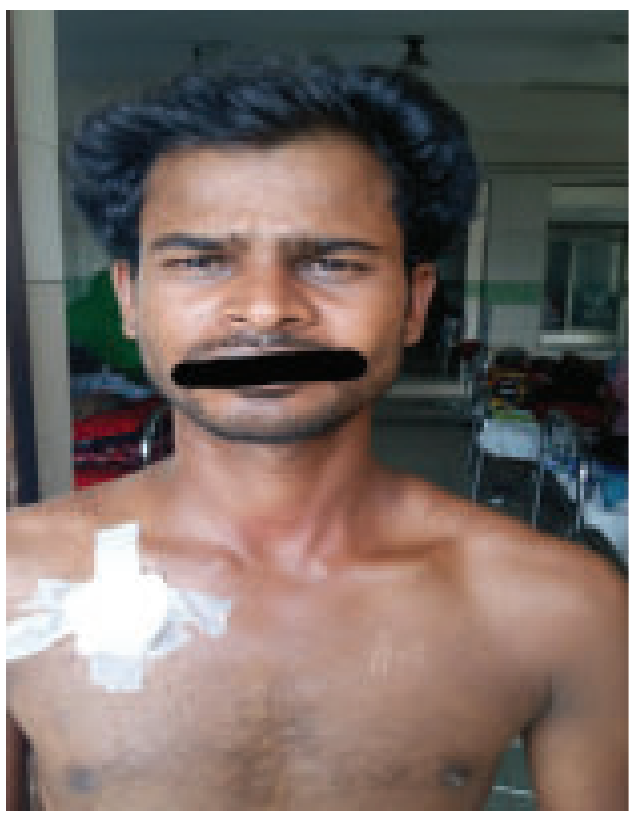

Case 2 (b) : after treatment

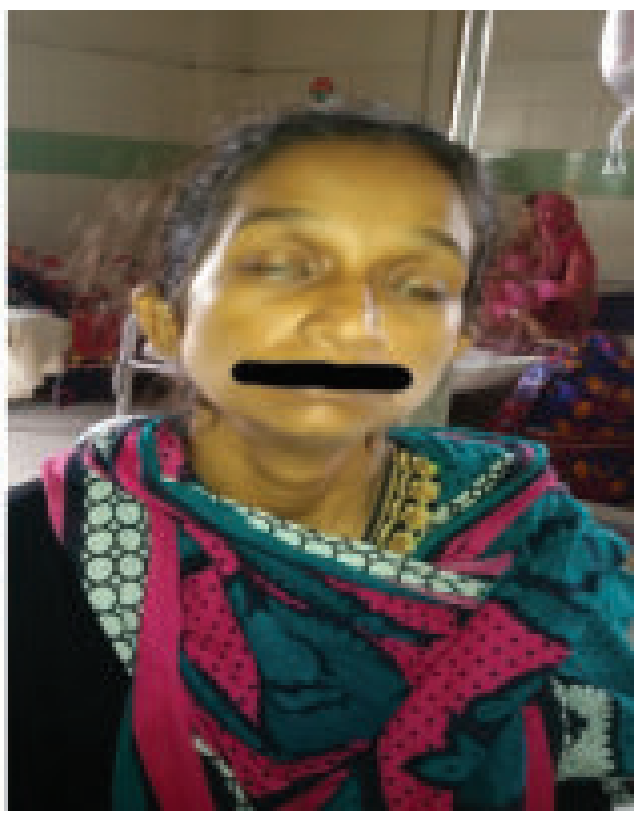

Case 3

Figure: Snake bite patients before and after treatment(case 1,2) and in case 3, before treatment 
Table: Features of 4 venomous snakes bite cases

\begin{tabular}{|c|c|c|c|c|}
\hline & Case 1 & Case 2 & Case 3 & Case 4 \\
\hline \multicolumn{5}{|l|}{ Clinical features } \\
\hline Site of bite & Left ear & Right hand & left middle finger & Right great toe \\
\hline local signs & none & Swollen & Swollen & none \\
\hline Fang mark & absent & absent & present & absent \\
\hline \multicolumn{5}{|l|}{ Vitals } \\
\hline GCS & 13 & 15 & 15 & 12 \\
\hline Pulse & 82 & 90 & 100 & 104 \\
\hline BP & $110 / 70$ & $100 / 60$ & $90 / 60$ & $120 / 70$ \\
\hline \multicolumn{5}{|l|}{ Neurological signs } \\
\hline Ptosis & Present & Present & Present & Present \\
\hline Nasal Voice & Absent & Present & Absent & Absent \\
\hline Broken neck sign & present & Absent & Absent & Present \\
\hline \multicolumn{5}{|l|}{ Investigations } \\
\hline Clotting time (min) & 7 & 6 & 7 & 8 \\
\hline TWC (cu mm) & 6700 & 9100 & 7800 & 11100 \\
\hline ESR (mm in 1st hr) & 10 & 21 & 40 & 60 \\
\hline \multicolumn{5}{|l|}{ LFT } \\
\hline Bilirubin (mg/dl & 0.8 & 1.2 & 1.5 & 2 \\
\hline $\operatorname{ALT}(\mathrm{U} / \mathrm{L})$ & 42 & 33 & 35 & 65 \\
\hline AST (U/L) & 50 & 40 & 47 & 30 \\
\hline Creatinine (mg/dl) & 0.9 & 1.1 & 1.1 & 1.3 \\
\hline \multicolumn{5}{|l|}{ Treatment } \\
\hline $\begin{array}{l}\text { Anti snake venom } \\
\text { (no of doses) }\end{array}$ & 2 & 3 & 1 & 3 \\
\hline \multicolumn{5}{|l|}{ Supportive treatment } \\
\hline $\begin{array}{l}(0.6 \mathrm{mg}) \\
\text { Inj. Neostigmine }\end{array}$ & Received & Received & Received & Received \\
\hline$(50 \mathrm{mcg} / \mathrm{kg})$ & Received & Received & Received & Received \\
\hline $\begin{array}{l}\text { ICU support } \\
\text { Mechanical }\end{array}$ & Provided & Provided & Provided & Provided \\
\hline Ventilation & Given & Not needed & Not needed & Given \\
\hline \multicolumn{5}{|l|}{ Complication of ASV } \\
\hline Anaphylaxis & No & No & No & Yes \\
\hline
\end{tabular}

\section{Discussion:}

This study was based on snake bite cases in a single medical unit of a tertiary level hospital. Most of the snake bite cases are nonpoisonous (86.2 \%). In a study by Faiz $72.5 \%$ was nonpoisonous snake bite. ${ }^{4}$ Probably this difference is due to large number of cases and study area around Chittagong Medical College Hospital which is hilly and full of venomous snakes. Our patients came from around areas of Dhaka city. In the present report the younger people are the victims with almost equal male to female ratio and this is a very small report to comment on this. The surveys done in Chittagong,
Rajshahi and Khulna depicted that the younger population were mostly affected with a male preponderance $3,7,8$. Outdoor activities of these groups may played a role. Studies regarding types of snake are inadequate but a survey in 198899 revealed Cobra bites was $34 \%$ of all bites ${ }^{9}$. In our report, though victim failed to bring the snake, by studying clinical features and syndromic approaches we suspected Krait as the culprit in majority cases (75\%). All victims had tight tourniquet to their limbs as a first aid management which were not done in appropriate method. This could lead to serious complications to patients though fortunately none 
developed so. It is recommended as per our national guidelines that application of tourniquet over a single bone for a brief period could be used as a first aid measure to prevent and delay the spread of venom in the systemic circulation. Most of the victims (75\%) received pre-hospital treatment from Ozhas (traditional healers) wasting valuable time. A study shows around $61 \%(\mathrm{n}=55)$ sought treatment from the traditional healers ${ }^{3}$. Titu et al in 2008 shows that $64 \%$ developed complications treated by traditional healers ${ }^{11}$.

We treated our cases with recommended dose of polyvalent Anti Snake Venom (ASV) following the national guideline. The outcome was excellent. Two out of 4 poisonous snake bite patients $(50 \%)$ developed respiratory failure requiring respiratory support in ICU and further administration of ASV reversed the patients. We administered highest 3 doses of ASV in one case who developed respiratory failure. One patient developed anaphylactic reaction and needed administration of adrenaline. We had no fatal outcome probably due to small number of cases.

A Study of Khulna Medical College showed that out of 108 venomous snake bite cases $101(93.52 \%)$ recovered completely and 7 (6.66\%) died after admission and 60 (55.5\%) cases recovered with $20-30 \mathrm{ml}$ (2-3 vials) of polyvalent ASV. ${ }^{8}$ A prospective study of hospital practice in the Gampaha district of Sri Lanka including 466 patients of whom 184 patients were venomous bite showed only 2 deaths $(0.43 \%)$ where at least 10 vials $(100 \mathrm{ml})$ of ASV was initially given. ${ }^{10}$ So it is justifiable to use antivenom in proper dose whenever indicated without fear of adverse reactions.

\section{Conclusion:}

Diagnosis of venomous snake bite cases and starting treatment with proper dosing of ASV with facilities to prevent complication is important to reduce number of death from snake bites. An adequate supply of ASV and other medicines should be made available to all the treatment facilities where snakebites are a problem. Larger and more studies are required to improve management of this important but neglected problem.

\section{Declarations}

a) Ethics approval and consent to participate:

Ethical approval not needed as it is a case series.

Consent had taken from every patient to publish in journal including image if needed. b) Availability of data and raw materials: All data analysed in this study are included in this published article.

c) Funding: It is a self funding research.

d) Competing interest: The authors declare that they have no competing interest.

e) Authors' contributions:

Rahman MM helps as guide in patient management, designing, compilation and making this case series.

Siddique AB participate in patient management, data collection, compilation and making this case series.

Kabir AKMH helps as guide in manuscript formatting, data collection.

Mallik MU helps as guide in data collection and manuscript formating.

Habibullah M participate in patient management, data collection, compilation and making this case series.

Mehedi MM participate in manuscript formatting

Chowdhury MK participate in patient management, data collection and compilation.

Acknowledgements: Not applicable.

\section{References:}

1. Gutiérrez JM, Williams D, Fan HW, Warrell DA. Snakebite envenoming from a global perspective: Towards an integrated approach. Toxicon. 2010; 56: 1223-1235 DOI: 10.1016/ j.toxicon.2009.11.020

2. KasturiratneA, Wickremasinghe AR, de Silva N, Gunawardena NK, Pathmeswaran A et al. Estimating the global burden of snakebite: A literature analysis and modelling based on regional estimates of envenoming and deaths. PLoS Med. 2008; 5: 218

3. Hossain J, Biswas A, Rahman F, Mashreky SR, Dalal K and Rahman A. Snakebite Epidemiology in Bangladesh-A National Community Based Health and Injury Survey. Health, 2016; 8: 479-486.

4. Rahman R, Faiz MA, Selim S, Rahman B, Basher A, Jones A et al. Annual Incidence of Snake Bite in Rural Bangladesh. PLoS Neglected Tropical Diseases. 2010; 4, e860. https:// doi.org/10.1371/journal.pntd.0000860

5. Faiz, MA., Hossain M, Amin R. National Guideline of Management of Snake Bite. 2008; 2nd Edition, DGHS, Dhaka.

6. Faiz MA, Rashid R, Gafur MA, Chowdhury MNH, Rahman MR, Das KK et al. Observation of 10 fatal cases following 
snake bite in Chittagong 1993-1998. Bangladesh J Med. 1999; 10: 30-33.

7. Islam QT, Faiz MA, Azhar MA, Ekram ARMS, Alam MT. Snake bite in the northern Bangladesh : a hospital based study of 68 cases.TAJ.1999; 12: 135-8

8. Abu Baker, Nazmul Ahasan, Manwar Ahsan. Snake bite in Bangladesh. Pak Armed Forces Med J. 2006; 56: 68-72

9. Warrell DA, Bhetwal BB, Chugh KS, Sjöström L et all. Guidelines for the clinical management of snake bites in the south east asia region, World Health Organization. Southeast
Asian Journal of Tropical Medicine \& Public Health, 1999;30

10. Seneviratne SL, Opanayaka CJ, Ratnayake NS, Kumara KE, Sugathadasa AM, Weerasuriya N, Wickrama WA, Gunatilake $\mathrm{SB}$, de Silva HJ. Use of antivenom serum in snake bite. A prospective study of hospital practice in Gampaha district. Ceylon Med J. 2000; 45: 65-8.

11. Miah MT, Hoque AA, Tarafder BK, Patwary MKH, Khan RR, Kabir SMEJ. Epidemiology, Clinical Profile and Outcome of Patients of Snake Bite in Mymensingh Medical College Hospital. J Bangladesh Coll Phys Surg 2009; 27: 70-75. 